\title{
Peribiliary cysts: diagnostic features on endoscopic ultrasound and digital cholangioscopy
}

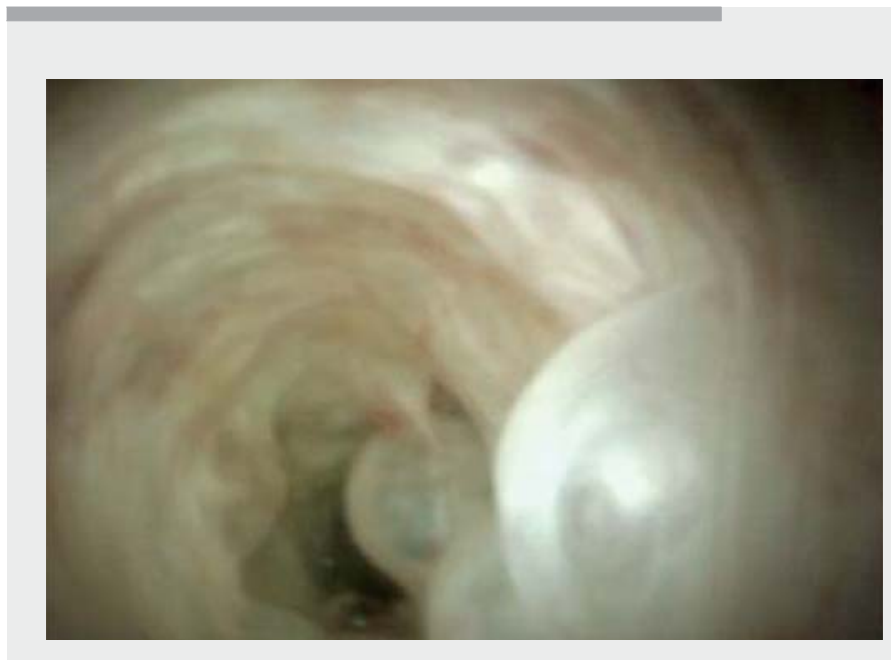

Video 1 Endoscopic ultrasound and cholangioscopy features of peribiliary cysts.

Various diseases have been associated with hepatobiliary cysts, such as autosomal dominant polycystic liver disease (ADPLD) and primary bile duct cysts. Acquired peribiliary cysts are however less well known. These cystic lesions may develop in the intrahepatic and/or extrahepatic bile duct wall and correlate with peribiliary gland ectasia on histology [1]. These intramural cysts may vary in size, typically ranging from $1 \mathrm{~mm}$ to $8 \mathrm{~mm}$, and should be considered a potential cause of bile duct compression and dilation [1-3]. While association with ADPLD has been described, alcohol-induced peribiliary gland injury is regarded as a major driver of peribiliary gland ectasia and subsequent cyst formation [1,2].

Patient 1, a 79-year-old patient with a history of alcoholic cirrhosis (Child-Pugh classification A), was referred to our center for investigation of intrahepatic and extrahepatic bile duct dilation, albeit without liver function abnormalities ( $\downarrow$ Video 1). Besides typical signs of cirrhosis, magnetic resonance imaging revealed diffuse bile duct dilation with ex- tensive caliber variations ( $>$ Fig. 1). Endoscopic ultrasound (EUS) subsequently identified extensive cystic abnormalities of the bile duct wall, without signs of intralesional flow (\Fig.2). Endoscopic retrograde cholangiopancreatography was performed and multiple cystic filling defects were revealed (> Fig. 3). Aiming to provide a definitive diagnosis, digital single-operator cholangioscopy was performed, confirming the presence of multiple intrahepatic and extrahepatic intraluminal cysts of varying dimensions ( $\triangleright$ Fig.4) and normal, nonneoplastic bile duct histology. Patient 2, a 65-year-old patient with a similar history of alcoholic cirrhosis (Child-Pugh classification C), underwent EUS for increased cholestasis and bile duct dilation. This showed a comparable image with scattered intramural cysts and bile duct dilation on EUS ( $\triangleright$ Fig.5). A diagnosis of peribiliary cysts was subsequently made in both patients, for which plastic stenting was performed in patient 2.

These two cases suggest that a diagnosis of peribiliary cysts should be considered

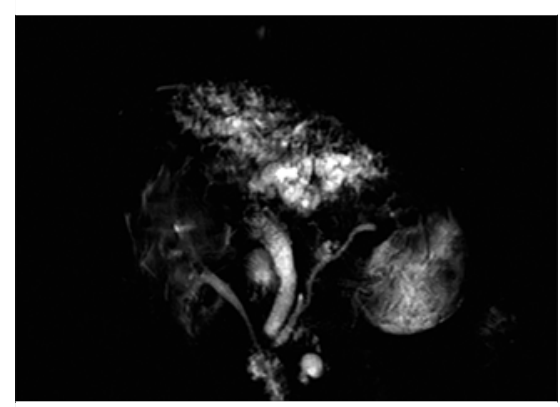

- Fig. 1 Patient 1. Magnetic resonance imaging (T2 RARE sequence) shows significant intrahepatic and extrahepatic bile duct lesions without clear signs of neoplasia or diffusion-restrictive lesions.

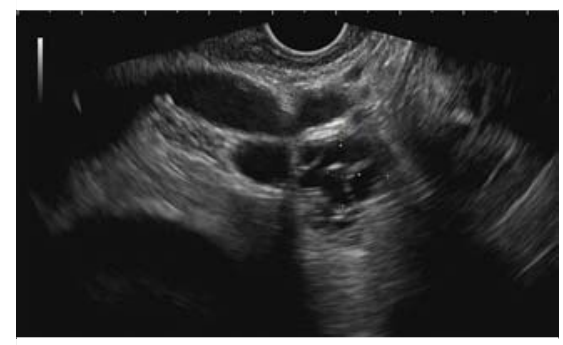

- Fig. 2 Patient 1. Endoscopic ultrasound shows multiple fluid-filled cystic lesions lining the common bile duct. No intralesional flow was identified by Doppler imaging.

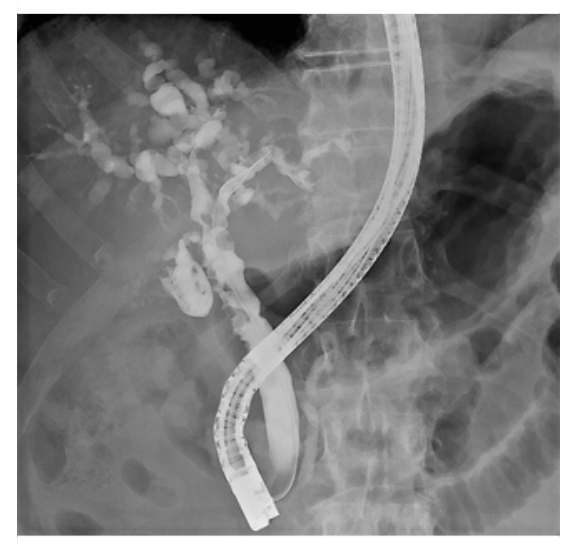

- Fig. 3 Patient 1. Fluoroscopy reveals multiple intrahepatic and extrahepatic filling defects and bile duct dilation. 


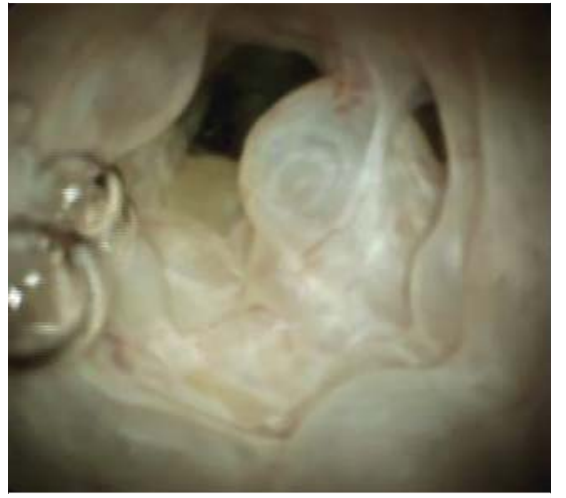

-Fig. 4 Patient 1. Digital single-operator cholangioscopy visualizes multiple clear fluid-filled cysts lining the common hepatic duct wall.

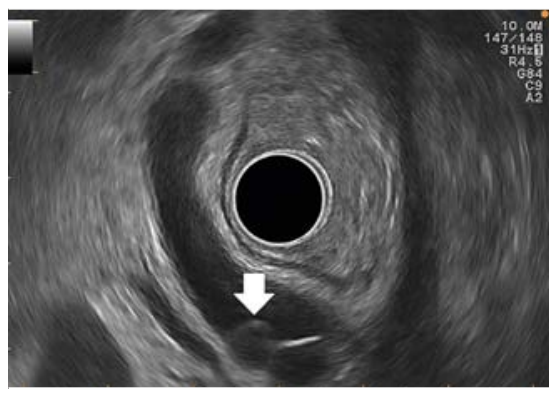

Fig. 5 Patient 2. Radial endoscopic ultrasound shows a fluid-filled cystic lesion of the common hepatic duct. Again, no intralesional flow was identified by Doppler imaging.

in patients with intrahepatic and/or extrahepatic bile duct dilation and underlying advanced liver disease.

Endoscopy_UCTN_Code_CCL_1AF_2AF
Michiel Bronswijk has received grants from Prion Medical, Taewoong, and Takeda, and has consultancy agreements with Prion Medical and Taewoong. Diederik Persyn, Thomas Billiet, and Ruben Spitaels declare no conflicts of interest. Hannah van Malenstein has consultancy agreements with Boston Scientific. Schalk Van der Merwe holds the Cook and Boston-Scientific chair in interventional endoscopy and holds consultancy agreements with Cook, Pentax, and Olympus.

The authors

Michiel Bronswijk ${ }^{1,2,3}$, Diederik Persyn ${ }^{1,4}$, Thomas Billiet ${ }^{5}$, Ruben Spitaels ${ }^{6}$, Hannah van Malenstein ${ }^{1}$, Schalk Van der Merwe ${ }^{1}$

1 Department of Gastroenterology and Hepatology, University Hospitals Leuven, Belgium

2 Department of Gastroenterology, Imelda General Hospital, Bonheiden, Belgium

3 Imelda Clinical GI Research Center, Bonheiden, Belgium

4 Department of Gastroenterology and Hepatology, AZ Damiaan, Oostende, Belgium

5 Department of Gastroenterology and Hepatology, AZ Groeninge, Kortrijk, Belgium

6 Department of Gastroenterology and Hepatology, Heilig Hart Ziekenhuis, Leuven, Belgium

\section{Corresponding author}

\section{Michiel Bronswijk, MD}

Department of Gastroenterology and Hepatology, University Hospitals Leuven, Herestraat 49, 3000 Leuven, Belgium mjh.bronswijk@gmail.com

\section{References}

[1] Pedica F, Heaton N, Quaglia A. Peribiliary glands pathology in a large series of endstage alcohol-related liver disease. Virchows Arch 2020; 477: 817-823

[2] Bazerbachi F, Haffar S, Sugihara T et al. Peribiliary cysts: a systematic review and proposal of a classification framework. BM] Open Gastroenterol 2018; 5: e000204

[3] Miyake H, Yuasa N, Kamiya J et al. Images in focus. Peribiliary cysts both in the cystic duct and in the intrahepatic biliary tract. Endoscopy 2001; 33: 643

Bibliography

Endoscopy 2022; 54: E476-E477

DOI 10.1055/a-1630-5921

ISSN 0013-726X

published online 1.10 .2021

(c) 2021. Thieme. All rights reserved.

Georg Thieme Verlag KG, Rüdigerstraße 14, 70469 Stuttgart, Germany

\section{ENDOSCOPY E-VIDEOS}

https://eref.thieme.de/e-videos

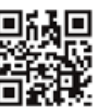

Endoscopy E-Videos is an open access online section, reporting on interesting cases and new techniques in gastroenterological endoscopy. All papers include a high quality video and all contributions are freely accessible online. Processing charges apply (currently EUR 375), discounts and wavers acc. to HINARI are available.

This section has its own submission website at https://mc.manuscriptcentral.com/e-videos 